\title{
Análise, por CLAE, de carotenóides de cinco linhagens de Rhodotorula
}

\author{
Fabio M. Squina, Adriana Z. Mercadante* \\ Departamento de Ciência de Alimentos, Faculdade de Engenharia de Alimentos, \\ Universidade Estadual de Campinas
}

*Correspondência:

A. Z. Mercadante

Departamento de Ciência de

Alimentos

Faculdade de Engenharia de Alimentos,

Universidade Estadual de Campinas

Caixa Postal 6121

13083-970 - Campinas - SPI

E-mail: azm@fea.unicamp.br
Um método por cromatografia líquida de alta eficiência (CLAE) foi otimizado para a análise da composição de carotenóides de cinco linhagens de Rhodotorula. A extração com ruptura mecânica da parede celular da levedura com areia tratada mostrou ser mais eficiente que a ruptura química com dimetilsulfóxido. Os carotenóides foram separados e quantificados por CLAE em coluna de $C_{18}$ utilizando como fase móvel acetonitrila/metanol $(0,1 \%$ trietilamina)/acetato de etila (75:15:10) e 100\% metanol $(0,1 \%$ trietilamina) entre as injeções, com vazão de $1 \mathrm{~mL} / \mathrm{min}$. Em todas as linhagens, os carotenóides majoritários encontrados foram torularrodina, toruleno, $\gamma$-caroteno e $\beta$-caroteno. Os teores totais de carotenóides, em $\mu \mathrm{g} / \mathrm{g}$, foram de 251,7 em R. glutinis, 123,5 em R. rubra, 113,2 em R. araucariae, 105,8 em R. lactosa e de 103,7 em R. minuta.

\section{INTRODUÇÃO}

Os carotenóides compõem um grupo de pigmentos naturais amplamente distribuídos na natureza com grande diversidade de estruturas e funções. Estes compostos têm sido amplamente utilizados como corantes nas indústrias de alimentos, farmacêutica, cosmética e de rações.

$\mathrm{O}$ interesse por carotenóides tem aumentado nos últimos anos devido à sua comprovada atividade próvitamínica A e pela evidência de outras propriedades biológicas, tais como atividades imunomoduladoras, anticarcinogênicas, prevenção de degeneração macular e de doenças cardiovasculares (Krinsky, 1994). Além disso, o mercado de corantes naturais tem se mostrado muito promissor, devido à tendência em se evitar alimentos que contenham aditivos artificiais. Os carotenóides também são fonte de pigmentação de peixes e crustáceos, sendo este, atualmente, o setor agropecuário com maior crescimento (Meyers, 1994; Johnson, Schroeder, 1995).

Existem vários fatores que dificultam a obtenção de dados confiáveis sobre a composição de carotenóides. Por apresentarem um longo sistema de ligações duplas conjugadas com elétrons $\pi$ deslocalizados, os carotenóides são altamente reativos e conseqüentemente instáveis. Além disso, número variado de carotenóides com estruturas muito diferentes pode ser encontrado em um único microrganismo. Devido a estas razões, a análise cromatográfica deste tipo de amostra é considerada complexa (Kester, 1984).

A separação dos carotenóides de Rhodotorula através de partição (Peterson et al., 1958) ou cromatografia em coluna aberta de $\mathrm{MgO} / \mathrm{Hyflosupercel} \mathrm{(Peterson} \mathrm{et} \mathrm{al.,}$ 1958; Simpson et al., 1964; Hayman et al., 1974) seguida de quantificação pelos espectros na região do visível foi 
realizada em alguns trabalhos nas décadas de 60 e 70 . Atualmente, a cromatografia líquida de alta eficiência (CLAE) tem se mostrado o método de escolha para separação e quantificação de carotenóides. Como existem poucos padrões de carotenóides disponíveis comercialmente, somente em um estudo (Nam et al., 1988) foi utilizada padronização externa por CLAE para quantificar os principais carotenóides de Rhodotorula. Para contornar esta dificuldade outras alternativas têm sido utilizadas, como a determinação do total de carotenóides espectrofotometricamente (Martelli et al., 1990; Martelli, Silva, 1993; Martin et al., 1993; Shih, Hang, 1996), das porcentagens relativas dos principais pigmentos por CLAE (Frengova et al., 1994, 1995; Buzzini, Martini, 1999) ou da quantidade de $\beta$-caroteno (Perrier et al., 1995).

Outra dificuldade encontrada está relacionada ao fato dos carotenóides nos microrganismos estarem localizados na parede celular, requisitando o isolamento da biomassa celular para posterior extração dos pigmentos por solventes orgânicos. A rigidez da parede celular de leveduras limita a extratibilidade dos carotenóides, sendo necessária a aplicação de métodos mecânicos (Simpson et al., 1964; Haard, 1988; Nam et al., 1988), químicos (Sedmak et al., 1990; Martin et al., 1993) ou enzimáticos (Johnson et al., 1978; Okagbue, Lewis, 1984) para recuperação desses pigmentos.

O objetivo deste trabalho foi a otimização de um método analítico para a determinação por CLAE da composição de carotenóides de leveduras Rhodotorula. O método foi utilizado para determinar a composição de carotenóides de cinco linhagens deste gênero.

\section{MATERIAL E MÉTODOS}

\section{Manutenção das Linhagens e Condições de Cultivo dos Microrganismos}

As linhagens da levedura Rhodotorula glutinis (CCT 2186), $R$. minuta (CCT 2187), $R$. araucariae (CCT 2123) e $R$. lactosa (CCT 2057) foram cedidas pela Fundação Tropical de Pesquisas "André Tosello". A linhagem de R. rubra foi obtida da coleção do Laboratório de Toxinas Microbianas da Faculdade de Engenharia de Alimentos, UNICAMP. Todas as cepas foram mantidas por repiques mensais em meios inclinados em tubos de ensaio contendo meio YM (Difco).

Para preparação do inóculo, frascos erlenmeyer de $500 \mathrm{~mL}$, contendo $50 \mathrm{~mL}$ de meio líquido $\mathrm{YM}$, inoculados com uma alçada das culturas em meio sólido, foram incubados a $150 \mathrm{rpm}$ sob temperatura de $28^{\circ} \mathrm{C}$ durante $24 \mathrm{~h}$.

Para cada linhagem em estudo, frascos erlenmeyer de $1000 \mathrm{~mL}$, contendo $100 \mathrm{~mL}$ de meio YM acrescidos de $10 \mathrm{~g} / \mathrm{L}$ de glicose foram inoculados com a suspensão de leveduras, anteriormente mencionada, correspondendo a $10 \%$ do volume total do cultivo. Estes frascos foram incubados à temperatura de $28^{\circ} \mathrm{C}$ a $150 \mathrm{rpm}$ de agitação, sob iluminação intensa com lâmpada fluorescente.

Após 5 dias, a massa celular de cada cultivo foi removida à velocidade de $3000 \mathrm{rpm}$, por $15 \mathrm{~min}$, em centrífuga (Sorval). Para eliminação de eventuais interferentes, a biomassa foi novamente ressuspendida em água destilada e centrifugada por mais duas vezes. As amostras de massa celular de leveduras foram congeladas, liofilizadas, pesadas e mantidas sob atmosfera de nitrogênio a $-18^{\circ} \mathrm{C}$, até análise.

\section{Extração dos Carotenóides}

Com o intuito de romper a parede celular das leveduras, testou-se dimetilsulfóxido (DMSO) e o uso de areia tratada, como descrito a seguir.

Utilizou-se a metodologia descrita por Sedmak et al. (1990), com algumas modificações. A levedura liofilizada (50 mg) foi agitada em Vortex por $1 \mathrm{~min}$ com 2,5 mL de DMSO a $55^{\circ} \mathrm{C}$, em tubo de vidro. Em seguida, adicionaram-se $5 \mathrm{~mL}$ de um solvente mais apolar, éter etílico (Martin et al., 1993), acetato de etila ou éter etílico/acetato de etila (1:1), e o tubo foi novamente agitado por 1 min e centrifugado a $3000 \mathrm{rpm}$ por $5 \mathrm{~min}$ para separação das fases. Este procedimento foi repetido, cerca de 6 vezes, até extração exaustiva dos carotenóides. As fases apolares foram reunidas e o extrato foi lavado com água destilada em funil de separação.

O tratamento da areia foi realizado no próprio laboratório e consistiu em destruição da matéria orgânica com $\mathrm{HCl} 50 \%$, sob aquecimento, lavagem até $\mathrm{pH}$ neutro, secagem, separação dos grãos de diâmetro de $0,5 \mathrm{~mm}$ a 1,0 $\mathrm{mm}$ e eliminação de metais ferromagnéticos com auxílio de um imã. Para extração dos carotenóides, quantidades iguais de levedura seca e areia $(250 \mathrm{mg}$ ) foram trituradas em gral e pistilo. Os carotenóides foram exaustivamente extraídos (cerca de 4 vezes) com total de $50 \mathrm{~mL}$ de acetato de etila, seguido de filtração em funil de filtro sinterizado.

Os extratos, obtidos pelos dois métodos, foram concentrados em evaporador rotatório $\left(\mathrm{T}<35^{\circ} \mathrm{C}\right)$, seguido de completa evaporação do solvente sob fluxo de nitrogênio.

\section{Padrões}

Os padrões de all-trans- $\gamma$-caroteno, all-trans- $\beta$ caroteno e all-trans-torularrodina foram gentilmente cedidos pela Hoffmann-La Roche (Basel, Suíça). 
O toruleno foi purificado a partir do extrato de carotenóides obtido de $R$. glutinis usando areia tratada como agente abrasivo ( $3 \mathrm{~g}$ da biomassa liofilizada de leveduras), como descrito anteriormente. Após evaporação do solvente, o extrato foi aplicado em coluna aberta de óxido de alumínio neutro (grau III). As frações 1 e 2, contendo carotenos, foram eluídas, respectivamente, com éter de petróleo e éter etílico/éter de petróleo (1:10).

A fração 2 foi separada por cromatografia em camada delgada de $\mathrm{MgO} / \mathrm{Kieselguhr}$ (1:1) em 4 zonas, utilizando como fase móvel acetona/éter de petróleo (1:1). A banda correspondente ao toruleno, de cor salmão e $\mathrm{R}_{\mathrm{f}}$ de 0,1 , foi raspada e o pigmento eluído com éter etílico. Verificou-se por CLAE que o grau de pureza do padrão de alltrans-toruleno foi de $95 \%$. O uso de coluna de $\mathrm{Ca}(\mathrm{OH})_{2}$ para separar os isômeros cis do all-trans-toruleno não foi eficiente para aumentar a pureza do isômero all-trans.

\section{Separação dos Carotenóides por CLAE}

Foi utilizado cromatógrafo líquido de alta eficiência com detector de arranjo de diodos (Waters, modelo 996), sistema quaternário de bombeamento de solventes (Waters, modelo Controller 600), injetor "Rheodyne" com alça de amostra de $20 \mu \mathrm{L}$, desgaseificador "on line" e sistema de aquisição e processamento de dados Millenium (Waters). A separação foi realizada em coluna $\mathrm{C}_{18}$ Novapack (4 $\mu \mathrm{m}, 4,6 \times 300 \mathrm{~mm})$, vazão de $1 \mathrm{~mL} / \mathrm{min}$ e temperatura da coluna mantida em forno a $29^{\circ} \mathrm{C}$. Os espectros foram adquiridos entre 250 e $600 \mathrm{~nm}$ e os cromatogramas processados a $460 \mathrm{~nm}$.

Após vários testes com combinações de acetonitrila, metanol, tetraidrofurano, diclorometano e acetato de etila, a composição da fase móvel utilizada para separação dos carotenóides foi $100 \%$ metanol ( $0,1 \%$ trietilamina) de 0 até 3,5 min, passando para acetonitrila/metanol $(0,1 \%$ trietilamina)/acetato de etila (88:10:2), em 30 segundos, e mantendo esta proporção até o final da análise (fase móvel 1). Posteriormente, a fase móvel foi modificada para acetonitrila/metanol ( $0,1 \%$ trietilamina)/acetato de etila (75:15:10), passando metanol $(0,1 \%$ trietilamina $)$ pela coluna por 1 minuto entre as injeções (fase móvel 2).

Todos os solventes utilizados foram grau cromatográfico e previamente filtrados em sistema Millipore de filtração a vácuo, com membrana para solvente orgânico de $0,45 \mu \mathrm{m}$. Todas as amostras também foram filtradas em membrana de polietileno com $0,22 \mu \mathrm{m}$ de poro.

\section{Identificação e Quantificação dos Carotenóides}

Para a identificação dos carotenóides, utilizaram-se as informações provenientes do comportamento cromatográfico desses pigmentos nos diferentes sistemas cromatográficos, co-cromatografia com padrões e comparação dos $\lambda_{\text {max }}$ dos espectros de absorção no UV-visível com valores da literatura (Davies, 1976; Britton, 1995). A estrutura fina do espectro (\%III/II) dos carotenóides foi calculada traçando como linha base o valor mínimo entre os picos III e II e medindo a altura do pico de maior comprimento de onda (III) e a altura do pico de absorção do meio (II), $\lambda_{\text {max }}$ para a maioria dos carotenóides, em relação à linha base (Britton, 1995).

A quantificação foi realizada pelo método do padrão externo. Foram construídas curvas-padrão com 5 diferentes concentrações para all-trans-toruleno (de 6,8 a $86,4 \mu \mathrm{g} / \mathrm{mL}$ ), all-trans-torularrodina (de 3,2 a $40,5 \mu \mathrm{g} / \mathrm{mL}$ ), all-trans- $\beta$-caroteno (de 6,6 a $84,8 \mu \mathrm{g} / \mathrm{mL}$ ) e all-trans- $\gamma$ caroteno (de 3,3 a $42,2 \mu \mathrm{g} / \mathrm{mL}$ ). As curvas obtidas dos padrões foram lineares nas faixas estudadas e as concentrações dos carotenóides nas amostras analisadas estavam dentre os valores das curvas-padrão. A quantificação dos carotenóides foi realizada por comparação da área do pico da amostra com o do padrão, injetado diariamente. O 16hidroxi-toruleno foi quantificado através dos valores de área obtidos para o toruleno.

\section{Avaliação do Método}

A precisão entre injeções foi verificada através de cinco injeções do mesmo extrato. A precisão do método também foi avaliada para todas as cepas.

Como não há padrão de referência certificado para carotenóides nesta matriz, a exatidão do método foi verificada através da adição à massa liofilizada de $R$. glutinis de $\beta$-caroteno nas quantidades de $5,7 \mu \mathrm{g}$ e $11,5 \mu \mathrm{g}$ e de torularrodina nos níveis de $5,6 \mu \mathrm{g}$ e $11,2 \mu \mathrm{g}$.

\section{RESULTADOS E DISCUSSÃO}

\section{Extração}

O DMSO mostrou-se bastante eficiente para baixas quantidades de amostra. Entretanto, quando maiores quantidades de levedura foram utilizadas, houve a formação de uma interface pigmentada e insolúvel, indicativa de extração incompleta. Este inconveniente já havia sido previamente relatado (Sedmak et al., 1990). No presente estudo, a utilização de éter etílico/acetato de etila (1:1) como solvente extrator mostrou maior eficiência e facilitou as etapas subseqüentes de centrifugação e lavagem.

A utilização de DMSO para liberação dos pigmentos das leveduras tem sido descrita em trabalhos envolven- 
do linhagens de Rhodotorula rubra (Martin et al., 1993), Rhodotorula glutinis (Buzzini, Martini, 1999) e Phaffia rhodozyma (Parajó et al., 1998), sendo considerado como método rápido e reprodutível (Sedmak et al., 1990). De fato, no presente trabalho o método empregando DMSO foi utilizado com sucesso para extração dos carotenóides de R. glutinis e R. rubra. Entretanto, não foi eficiente para extração exaustiva dos pigmentos de $R$. minuta, além do fato de que o uso de solvente a $55^{\circ} \mathrm{C}$ para o rompimento das leveduras pode ser crítico, uma vez que os carotenóides são instáveis à temperatura.

Diferenças na eficiência de extração de diferentes linhagens de Rhodotorula também foram reportadas no estudo conduzido por Peterson et al. (1958). A extração com acetona sob agitação vigorosa foi completa para $R$. glutinis variedades rubescens e flava, enquanto que a eficiência foi de 80 a $90 \%$ para $R$. mucilaginosa e $R$. glutinis, de 50 a $60 \%$ para $R$. rubra, e muito baixa para $R$. minuta e $R$. aurantiaca (Peterson et al., 1958).

No presente estudo, a trituração da biomassa seca de leveduras com areia tratada promoveu a extração exaustiva de até $2 \mathrm{~g}$ de amostra seca com acetato de etila, sem necessidade de aquecimento, e foi eficiente para todas as cepas estudadas. Comparativamente, este método propiciou a extração de maiores quantidades de carotenóides, utilizando menores quantidades de solvente e foi o escolhido para a análise subseqüente das diferentes cepas. Embora Haard (1988) também tenha utilizado areia para extração de carotenóides de Phaffia rhodozyma, são raros os trabalhos que utilizam este tipo de método para extração de carotenóides de leveduras.

\section{Separação por CLAE}

A separação dos carotenóides utilizando gradiente (fase móvel 1) ocorreu em 60 minutos, além de serem necessários mais 15 minutos para recondicionamento da coluna. Por outro lado, a fase móvel 2 apresentou separação similar em 40 minutos de corrida (Figura 1a). A identificação dos picos e as estruturas dos carotenóides estão apresentadas na Tabela I e Figura 2, respectivamente.

Cabe ressaltar que foi necessário adicionar, no mínimo, $80 \%$ de metanol na composição da fase móvel para eluição da torularrodina. Como mostra a Figura 1b, não houve eluição deste carotenóide utilizando a fase móvel 2 sem condicionamento da coluna com metanol. Possivelmente, a formação de ligações de hidrogênio entre o grupo carboxílico da torularrodina e o metanol justifique tal comportamento cromatográfico. Não foi observada diferença nas concentrações de carotenóides quando os carotenóides foram separados com as diferentes fases móveis (Tabela II).
É interessante ressaltar a presença de isômeros cis de todos os carotenóides em todas as linhagens analisadas. Apesar da forma trans possuir maior estabilidade, a presença de isômeros cis é justificada pelo cultivo ter sido realizado sob intensa iluminação, uma vez que é amplamente conhecido que a luz é um dos principais catalisadores na reação de isomerização de carotenóides.

Recentemente, os carotenóides de Rhodotorula glutinis foram separados por CLAE em coluna de $\mathrm{C}_{18}$ (Nam et al., 1988; Frengova et al., 1994; Perrier et al., 1995; Buzzini, Martini, 1999). Entretanto, o cromatograma foi apresentado somente no trabalho de Nam et al. (1988), que não separou os isômeros geométricos da torularrodina, toruleno, $\gamma$-caroteno e $\beta$-caroteno.

\section{Desempenho do Método}

A área de cada carotenóide foi obtida pela soma das áreas dos seus isômeros geométricos cis e trans. Os valores do coeficiente de variação $(\mathrm{CV})$ entre cinco injeções foram de $0,9 \%$ para torularrodina, $1,0 \%$ para toruleno, $1,5 \%$ para $\gamma$-caroteno e $0,7 \%$ para $\beta$-caroteno. Estes valores de $\mathrm{CV}$ foram menores que os apresentados por Nam et al. (1988) para triplicatas de injeções, cujos valores de CV foram de $13 \%$ para torularrodina, $4 \%$ para toruleno, $3 \%$ para $\gamma$-caroteno e $0,4 \%$ para $\beta$-caroteno

Como esperado, o CV entre duplicatas de extrações foi maior, sendo $3,5 \%$ para torularrodina, $6,2 \%$ para toruleno, $4,3 \%$ para $\gamma$-caroteno e $4,5 \%$ para $\beta$-caroteno.

A recuperação do $\beta$-caroteno foi de $96 \%$ e $97 \%$ nos níveis de menor e maior concentração, respectivamente. A recuperação da torularrodina foi de $94 \%$ no nível de menor concentração e de $83 \%$ no nível de maior concentração.

Os valores de CV das análises estão bem abaixo dos relatados na literatura para carotenóides de frutas (Hamano, Mercadante, 2001; Assunção, Mercadante, 2003), cenoura (Bushway, Wilson, 1982) e vegetais (Scott et al., 1996); e a recuperação de $\beta$-caroteno está na faixa descrita (Assunção, Mercadante, 2003). O desempenho dos métodos utilizados na análise de carotenóides de Rhodotorula não foi reportado na literatura (Nam et al., 1988; Frengova et al., 1994; Perrier et al., 1995; Buzzini, Martini, 1999).

\section{Composição de Carotenóides de Cinco Linhagens de Rhodotorula}

O perfil de carotenóides foi semelhante para as cinco cepas, apresentando como carotenóides majoritários $\beta$ caroteno, $\gamma$-caroteno, toruleno e torularrodina (Tabela III), 

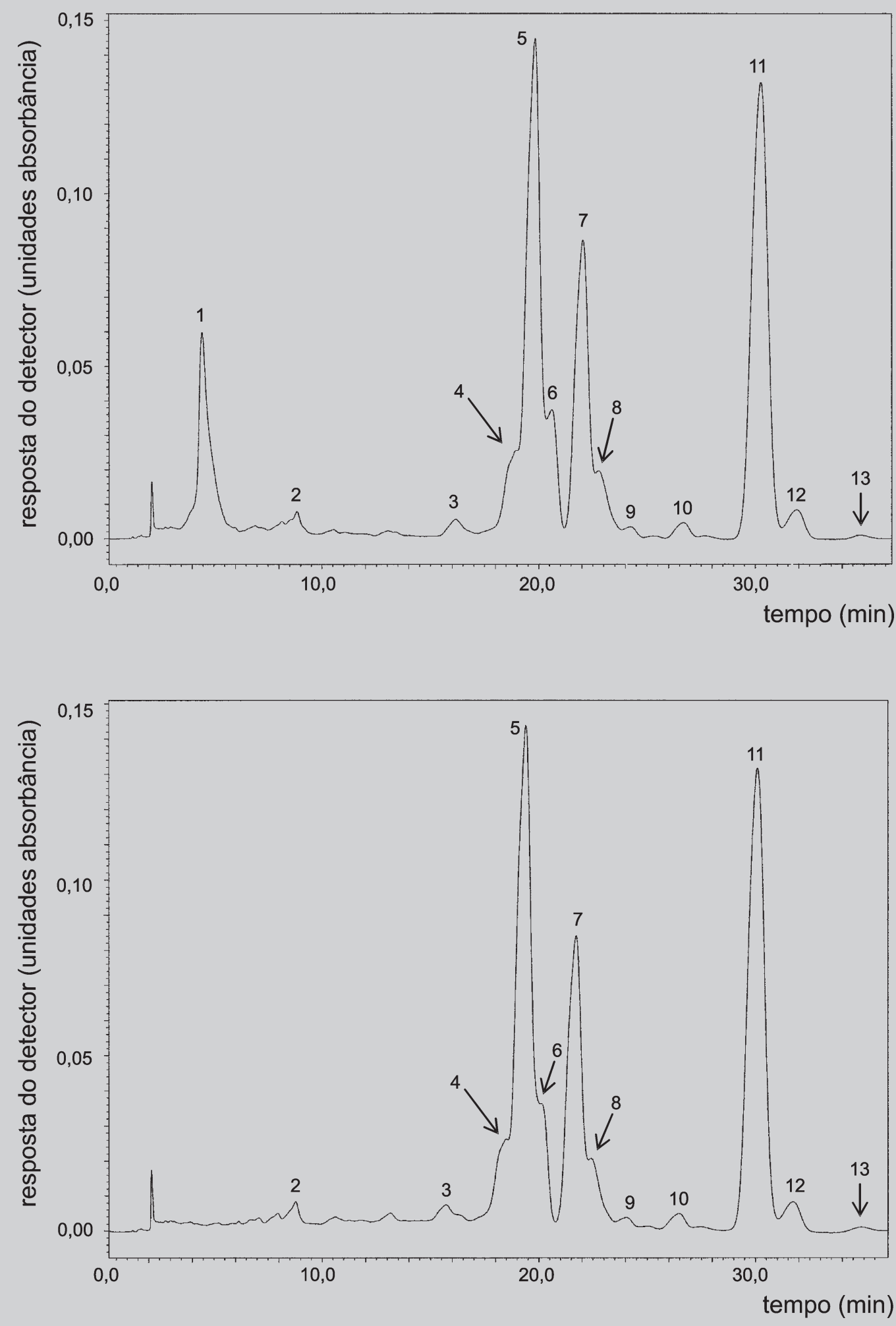

FIGURA 1 - Cromatograma, obtido por CLAE, dos carotenóides de $R$. glutinis. Condições: coluna Novapack $\mathrm{C}_{18}(4 \mu \mathrm{m}$, 4.6 x $300 \mathrm{~mm}$ ), fase móvel acetonitrila/metanol (0,1\% trietilamina)/acetato de etila (75:15:10), vazão de $1 \mathrm{ml} / \mathrm{min} \mathrm{e}$ temperatura da coluna de $29{ }^{\circ} \mathrm{C}$; a- com eluição de metanol (0,1\% trietilamina) por 1 minuto entre as injeções, b- sem eluição de metanol entre injeções. A identificação dos picos encontra-se na Tabela I. 
TABELA I - Características dos carotenóides das cinco linhagens de Rhodotorula

\begin{tabular}{|c|c|c|c|c|}
\hline $\mathrm{n}^{\circ}$ do pico ${ }^{\mathrm{a}}$ & carotenóides & $t_{R}(\min )^{b}$ & $\lambda_{\max }(\mathrm{nm})^{\mathrm{c}}$ & $\%$ III/II \\
\hline 1 & torularrodina & $4,0-4,6$ & $387,(465), 492,524$ & 30 \\
\hline 2 & 16-hidroxi-toruleno & $8,8-9,2$ & $381,(460), 487,520$ & 31 \\
\hline 3 & não identificado & $15,9-16,6$ & $374,(450), 476,506$ & 28 \\
\hline 4 & neurosporeno & $18,3-18,9$ & $415,442,471$ & 98 \\
\hline 5 & all-trans-toruleno & $19,6-20,4$ & $381,460,488,521$ & 49 \\
\hline 6 & cis-toruleno & $20,5-22,0$ & $378,(456), 482,514$ & 29 \\
\hline 7 & all-trans- $\gamma$-caroteno & $21,9-23,0$ & $437,464,493$ & 52 \\
\hline 8 & $c i s-\gamma$-caroteno & $22,4-23,6$ & $350,(432), 460,488$ & 23 \\
\hline 9 & $\zeta$-caroteno & $24,5-25,9$ & $376,398,422$ & 106 \\
\hline 10 & $\beta$-zeacaroteno & $26,9-28,3$ & $(406), 430,456$ & 53 \\
\hline 11 & $\beta$-caroteno & $30,2-31,6$ & $(430), 454,481$ & 21 \\
\hline 12 & 15 -cis- $\beta$-caroteno & $31,9-33,3$ & $339,(423), 448,478$ & 0 \\
\hline 13 & fitoeno & $35,0-36,0$ & $(275), 287,302$ & 0 \\
\hline
\end{tabular}

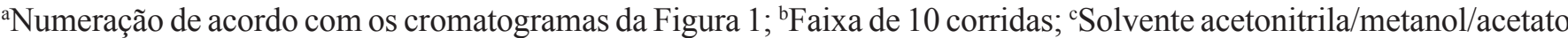

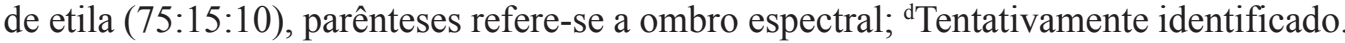

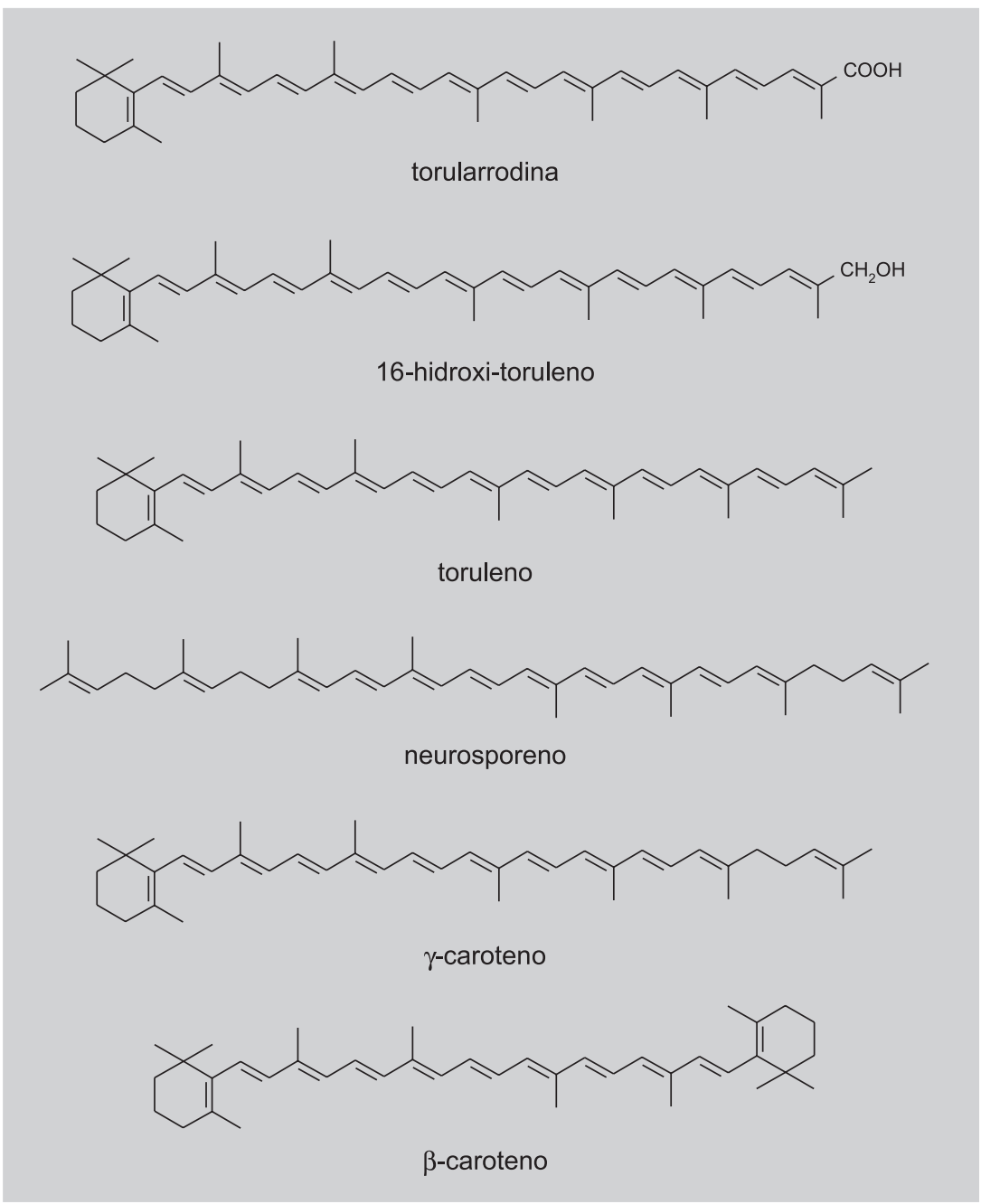

FIGURA 2 - Estrutura dos carotenóides presentes em Rhodotorula. 
TABELA II - Composição de carotenóides de R. glutinis

\begin{tabular}{|c|c|c|}
\hline \multirow[t]{2}{*}{ Carotenóides } & \multicolumn{2}{|c|}{ concentração ( $\mu \mathrm{g} / \mathrm{g}$ de massa seca) ${ }^{a}$} \\
\hline & FM1 & FM2 \\
\hline torularrodina & $33,2 \pm 1,6$ & $26,0 \pm 3,5$ \\
\hline 16-hidroxi-toruleno ${ }^{\mathrm{b}}$ & $2,6 \pm 0,1$ & $2,7 \pm 0,7$ \\
\hline toruleno + neurosporeno & $111,6 \pm 4,2$ & $108,1 \pm 7,5$ \\
\hline$\gamma$-caroteno & $34,1 \pm 1,2$ & $48,5 \pm 4,0$ \\
\hline$\beta$-caroteno & $69,9 \pm 0,6$ & $66,4 \pm 3,8$ \\
\hline total & $251,3 \pm 7,7$ & $251,7 \pm 19,5$ \\
\hline
\end{tabular}

FM1: fase móvel 1, 100\% metanol (0,1\% trietilamina) de 0 até $3,5 \mathrm{~min}$, passando para acetonitrila/metanol $(0,1 \%$ trietilamina)/acetato de etila (88:10:2) em 30 segundos, e mantendo esta proporção até o final da análise.

FM2: fase móvel 2, acetonitrila/metanol (0,1\% trietilamina)/acetato de etila (75:15:10), eluindo a coluna por 1 minuto com metanol $(0,1 \%$ trietilamina) entre as injeções.

${ }^{a}$ Os valores correspondem à média e desvio-padrão de duplicatas de extração e de quantificação por CLAE. ${ }^{\mathrm{b}}$ Tentativamente identificado.

TABELA III - Composição de carotenóides ( $\mu \mathrm{g} / \mathrm{g}$ de massa seca) de quatro linhagens de Rhodotorula

\begin{tabular}{lcccc}
\hline Carotenóides & $\boldsymbol{R}$. rubra & $\boldsymbol{R}$. araucariae & $\boldsymbol{R}$. lactosa & $\boldsymbol{R}$. minuta \\
\hline torularrodina & $63,3 \pm 7,8$ & $31,5 \pm 24$ & $23,8 \pm 0,3$ & $35,6 \pm 0,8$ \\
16-hidróxi-toruleno & $2,2 \pm 0,4$ & $1,6 \pm 0,2$ & $1,4 \pm 0,2$ & $1,2 \pm 0,1$ \\
toruleno + neurosporeno $^{\mathrm{a}}$ & $40,9 \pm 5,0$ & $49,3 \pm 1,4$ & $56,8 \pm 2,1$ & $47,4 \pm 4,7$ \\
-caroteno $_{\beta \text {-caroteno }}$ & $1,2 \pm 0,3$ & $6,2 \pm 0,2$ & $6,3 \pm 0,1$ & $5,3 \pm 0,1$ \\
total & $15,9 \pm 1,9$ & $24,6 \pm 0,5$ & $17,5 \pm 0,2$ & $14,2 \pm 1,7$ \\
\hline
\end{tabular}

Os valores correspondem à média e desvio-padrão de duplicatas de extração e de quantificação por CLAE, utilizando como fase móvel acetonitrila/metanol ( $0,1 \%$ trietilamina)/acetato de etila (75:15:10) e eluição por 1 minuto com metanol

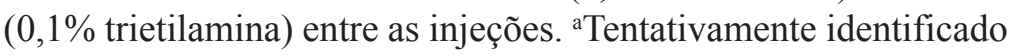

que são característicos deste gênero (Simpson et al., 1964; Britton, 1998). Os carotenóides minoritários detectados no presente trabalho, $\zeta$-caroteno, $\beta$-zeacaroteno, neurosporeno e fitoeno, são intermediários da via biossintética (Peterson et al., 1958; Britton, 1998).

O total de carotenóides assim como as quantidades relativas dos pigmentos individuais variaram em função da cepa de Rhodotorula e das diferentes condições do meio de cultivo (Squina et al., 2002).

As porcentagens de torularrodina (10\%), toruleno (43\%), $\gamma$-caroteno (19\%) e $\beta$-caroteno $(26 \%)$ em $R$. glutinis, obtidas no presente estudo, apresentaram concordância com outros estudos utilizando meios de cultivo de leveduras comuns em laboratórios de microbiologia, que apresentaram para os respectivos carotenóides citados teores variando de 24 a 29\%, 27 a 37\%, 9 a 12\% e 15 a 27\% (Peterson et al., 1958; Simpson et al., 1964). Em outro estudo (Squina et al., 2002) envolvendo o cultivo de $R$. glutinis da mesma procedência em diferentes composições de meio de cultura contendo caldo de cana-de-açúcar, as porcentagens variaram de 5 a $16 \%$ de torularrodina, de 26 a $46 \%$ de toruleno, de 5 a $17 \%$ de $\gamma$-caroteno e de 33 a $50 \%$ de $\beta$-caroteno. Utilizando diferentes fontes alternativas de carboidratos, as porcentagens variaram de 74 a $85 \%$ de torularrodina, de 7,9 a $14,8 \%$ de toruleno e de 0 a $25 \%$ de $\beta$-caroteno em relação ao total de carotenóides de $R$. glutinis (Buzzini, Martini, 1999). Dois tipos de perfis de carotenóides para $R$. glutinis são encontrados na literatura, sendo um com níveis de torularrodina acima de 55\% (Peterson et al., 1958; Frengova et al., 1994, 1995; Buzzini, Martini, 1999), e outro com níveis deste pigmento abaixo de $40 \%$ (Peterson et al., 1958; Simpson et al., 1964; Hayman et al., 1974; Nam et al., 1988; Squina et al., 2002), sendo que Nam et al. (1988) obtiveram níveis de $2 \%$ deste pigmento. 
O total de carotenóides $(251,7 \mu \mathrm{g} / \mathrm{g})$ obtido no presente estudo para $R$. glutinis foi próximo ao obtido por Simpson et al. (1964) utilizando substratos microbiológicos $(235,2$ e $256,7 \mu \mathrm{g} / \mathrm{g})$. Porém, o total produzido por esta cepa no presente estudo foi menor que o obtido por Peterson et al. (1958) (332,0 e 494,0 $\mu \mathrm{g} / \mathrm{g})$ e maior que os obtidos por Perrier et al. (1995) $(70 \mu \mathrm{g} / \mathrm{g})$ e Nam et al. (1988) $(79,5 \mu \mathrm{g} / \mathrm{g})$, também utilizando meios comuns de cultivo para leveduras.

A Tabela III apresenta a composição para R. rubra, cujos resultados para as porcentagens dos pigmentos torularrodina $(51 \%)$, toruleno $(33 \%), \gamma$-caroteno $(1 \%)$ e $\beta$ caroteno (13\%) foram similares às verificadas no estudo de Peterson et al. (1958), que apresentou, respectivamente, $49 \%, 28 \%, 9 \%$ e $15 \%$. O total de pigmentos por peso seco obtido no presente trabalho $(123,5 \mu \mathrm{g} / \mathrm{g})$ foi próximo ao total obtido para $R$. rubra NRRL-15596 cultivada em salmoura produzida na fermentação do repolho $(130 \mu \mathrm{g} / \mathrm{g})$ (Shih, Hang, 1996). A mesma linhagem de R. rubra do presente estudo produziu de 60,0 a 426,6 $\mu \mathrm{g} / \mathrm{g}$ de carotenóides totais, dependendo da composição do meio de cultivo (Squina et al., 2002).

Embora a quantidade de $\beta$-caroteno de $R$. araucariae obtida no presente estudo (Tabela III) tenha sido próxima da determinada por Perrier et al. (1995) $(30 \mu \mathrm{g} / \mathrm{g})$, o total de carotenóides foi quase o triplo do reportado $(40 \mu \mathrm{g} / \mathrm{g})$ por este autores.

A cepa $R$. lactosa avaliada no presente trabalho (Tabela III) apresentou cerca de um terço do conteúdo de $\beta$ caroteno $(17,5 \mu \mathrm{g} / \mathrm{g})$ e total de carotenóides $(105,8 \mu \mathrm{g} / \mathrm{g})$ superior aos teores encontrados por Perrier et al. (1995), respectivamente, de 55 e $75 \mu \mathrm{g} / \mathrm{g}$. O total de carotenóides desta levedura cultivada em soro de leite foi de $86,7 \mu \mathrm{g} / \mathrm{g}$ (Frengova et al., 1994).

Em relação a $R$. minuta (Tabela III), as porcentagens relativas obtidas neste trabalho para torularrodina (34\%), toruleno $(46 \%), \gamma$-caroteno $(5 \%)$ e $\beta$-caroteno $(14 \%)$ foram similares às relatadas previamente por Peterson et al. (1958) (38\%, 41\%, 7\% e 14\% para os respectivos carotenóides). O total de carotenóides obtido para esta cepa no presente trabalho $(104 \mu \mathrm{g} / \mathrm{g})$ foi também próximo ao reportado por Peterson et al. (1958) $(93,4 \mu \mathrm{g} / \mathrm{g})$ e maior que o teor relatado por Perrier et al. (1995) $(40 \mu \mathrm{g} / \mathrm{g})$.

\section{CONCLUSÕES}

Os resultados demonstraram que, além do método otimizado de análise ser preciso e exato, os cultivos foram bem controlados e reproduzidos. Todos os pigmentos quantificados apresentaram-se ao redor da média com um intervalo de confiança de $90 \%$.
Das cepas avaliadas, $R$. glutinis foi a que apresentou a maior concentração de carotenóides, seguido da $R$. rubra. Os carotenóides principais encontrados foram torularrodina, toruleno, $\gamma$-caroteno e $\beta$-caroteno em todas as linhagens. Entretanto, as cepas apresentaram diferenças quantitativas marcantes para os principais pigmentos.

\section{AGRADECIMENTOS}

Os autores agradecem à CAPES, pela bolsa de Mestrado ao primeiro autor, e ao CNPq e Roche Vitamins Ltd., pelo auxílio financeiro.

\section{ABSTRACT}

\section{HPLC analysis of carotenoids from five Rhodotorula strains}

A method for extraction and HPLC separation of carotenoids from five Rhodotorula strains was optimized. The extraction by mechanical disruption of the yeast cell wall with fine treated sand was shown to be more efficient than chemical disruption with dimethylsulfoxide. The carotenoids were separated and quantified by HPLC on a $C_{18}$ column using as mobile phase acetonitrile/methanol $(0.1 \%$ triethylamina)/ethyl acetate $(75: 15: 10)$ with $100 \%$ methanol (0.1\% triethylamine) between the injections, at a flow rate of $1.0 \mathrm{~mL} / \mathrm{min}$. In all strains, the major carotenoids found were torularhodin, torulene, $\gamma$-carotene and $\beta$ carotene. The total carotenoid contents, in $\mu \mathrm{g} / \mathrm{g}$, obtained were 251.7 for $\mathrm{R}$. glutinis, 123.5 for $\mathrm{R}$. rubra, 113.2 for $\mathrm{R}$. araucariae, 105.8 for $\mathrm{R}$. lactosa and 103.7 for $\mathrm{R}$. minuta.

UNITERMS: Carotenoids. Rhodotorula. HPLC.

\section{REFERÊNCIAS BIBLIOGRÁFICAS}

ASSUNÇÃO, R. B.; MERCADANTE, A. Z. Carotenoids and ascorbic acid from cashew apple (Anacardium occidentale L). Food Chem., Amsterdam, v.81, p.495$502,2003$.

BRITTON, G. Overview of carotenoid biosynthesis. In: BRITTON, G.; LIAAEN-JENSEN, S.; PFANDER, H., eds. Carotenoids: biosynthesis and metabolism. Basel: Birkhäuser Verlag, 1998. v.3., p.13-147.

BRITTON, G. UV/Visible spectroscopy. In: BRITTON, G.; LIAAEN-JENSEN, S.; PFANDER, H., eds. Carotenoids: spectroscopy. Basel: Birkhäuser Verlag, 1995. v.1B, p.13-62. 
BUSHWAY, R. J.; WILSON, A. M. Determination of $\alpha$ - and $\beta$-carotene in fruit and vegetables by high performance liquid chromatography. Can. Inst. Food. Sci. Technol. J., Ottawa, v.15, p.165-169, 1982.

BUZZINI, P.; MARTINI, A. Production of carotenoids by strains of Rhodotorula glutinis cultured in raw materials of agro-industrial origin. Bioresour. Technol., Amsterdam, v.71, p.41-44, 1999.

DAVIES, B. H. Carotenoids. In: GOODWIN, T. W., ed. Chemistry and biochemistry of plant pigments. 2.ed. London: Academic Press, 1976. v.2, p.38-165.

FRENGOVA, G.; SIMOVA, E.; PAVALOVA, K.; BESHKOVA, D.; GRIGOROVA, D. Formation of carotenoids by Rhodotorula glutinis in whey ultrafiltrate. Biotechnol. Bioeng., New York, v.44, p.888-894, 1994.

FRENGOVA, G. I.; SIMOVA, E. D.; BESHKOVA, D. M. Effect of temperature changes on the production of yeast pigments co-cultivated with lacto-acid bacteria in whey ultrafiltrate. Biotechnol. Lett., Dordrecht, v.17, p.10011006, 1995.

HAARD, N. F. Astaxanthin formation by the yeast Phaffia rhodozyma on molasses. Biotechnol. Lett., Dordrecht, v.10, p.609-614, 1988.

HAMANO, P. S.; MERCADANTE, A. Z. Composition of carotenoids from commercial products of caja (Spondias luteas). J. Food Compos. Anal., Orlando, v.14, p.335343, 2001.

HAYMAN, E. P.; YOKOYAMA, H.; CHICHESTER, C.; SIMPSON, K. L. Carotenoid biosynthesis in Rhodotorula glutinis. J. Bacteriol., Washington, v.120, p.1339-1343, 1974.

JOHNSON, E. A.; SCHROEDER, W. A. Microbial carotenoids. Adv. Biochem. Eng./Biotechnol., Berlin, v.53, p.119-178, 1995.

JOHNSON, E. A.; VILLA, T. G.; LEWIS, M. J.; PHAFF, H. J. Simple method for the isolation of astaxanthin from the Basidiomycetous yeast Phaffia rhodozyma. Appl. Environ. Microbiol., Washington, v.35, p.1155-1158, 1978.
KESTER, A. S. Computer-optimized normal-phase highperformance liquid chromatographic separation of corynebacterium poinsettiae carotenoids. $J$. Chromatogr., Amsterdam, v.310, p.372-378, 1984.

KRINSKY, N. I. The biological properties of carotenoids. Pure Appl. Chem., Research Triangle Park, v.66, p.10031010, 1994.

MARTELLI, H.; SILVA, I. M. Beta-carotene synthesis in Rhodotorula. Methods Enzymol., San Diego, v.214, p.386-390, 1993.

MARTELLI, H. L.; SILVA, I. M.; SOUZA, N. O.; POMEROY, D. Production of $\beta$-carotene by a Rhodotorula strain grown on sugar cane juice. Biotechnol. Lett., Dordrecht, v.12, p.207-208, 1990.

MARTIN, A. M.; LU, C.; PATEL, T. R. Growth parameters for the yeast Rhodotorula rubra grown in peat extracts. J. Ferment. Bioeng., Amsterdam, v.76, p.321-325, 1993.

MEYERS, S. P. Developments in world aquaculture, feed formulation, and role of carotenoids. Pure Appl. Chem., Research Triangle Park, v.66, p.1069-1976, 1994.

NAM, H. S.; CHO, S. Y.; RHEE, J. S. High-performance liquid chromatographic analysis of major carotenoids from Rhodotorula glutinis. J. Chromatogr., Amsterdam, v.448, p.445-447, 1988.

OKAGBUE, R. N.; LEWIS, M. J. Autolysis of the red yeast Phaffia rhodozyma: a potential tool to facilitate extraction of astaxanthin. Biotechnol. Lett., Dordrecht, v.6, p.247250, 1984.

PARAJÓ, J. C.; SANTOS, V.; VAZQUEZ, M. Optimization of carotenoid production by Phaffia rhodozyma cells grown on xylose. Process Biochem., Oxford, v.33, p.181187, 1998.

PERRIER, V.; DUBREUCQ, E.; GAYZY, P. Fatty acid and carotenoid composition of Rhodotorula strains. Arch. Microbiol., Berlin, v.164, p.173-179, 1995.

PETERSON, W. J.; LECCE, E. E.; BELL, T. A.; ETCHELLS, J. L. Quantitative determination of the carotenoids in yeasts of the genus Rhodotorula. $J$. Bacteriol., Washington, v.75, p.586-591, 1958. 
SCOTT, K. J.; FINGLAS, P. M.; SEALE, R.; HART, D. J.; FROIDMONT-GÖRTZ, I. Interlaboratory studies of HPLC procedures for the analysis of carotenoids in foods. Food Chem., Amsterdam, v.57, p.85-90, 1996.

SEDMAK, J. J.; WEERASINGHE, D. K.; JOLLY, S. O. Extraction and quantitation of astaxanthin from Phaffia Rhodozyma. Biotechnol. Tech., London, v.4, p.107-112, 1990.

SHIH, C. T.; HANG, Y. D. Production of carotenoids by Rhodotorula rubra from sauerkraut brine. Lebensm.Wiss. Technol., London, v.29, p.570-572, 1996.
SIMPSON, K. L.; NAKAYAMA, T. O. M.; CHICHESTER, C. O. Biosynthesis of yeast carotenoids. J. Bacteriol., Washington, v.88, p.1688-1094, 1964.

SQUINA, F. M.; YAMASHITA, F.; PEREIRA, J. L.; MERCADANTE, A. Z. Production of carotenoids by Rhodotorula rubra and $R$. glutinis in culture medium supplemented with sugar cane juice. Food Biotechnol., New York, v.16, p.227-235, 2002.

Recebido para publicação em 26 de março de 2003. 